\title{
Modelos, plantillas, trazas y monteas en los contratos para la construcción del Monasterio de San Lorenzo del Escorial
}

\author{
Scale models, templates, drawings, and full-scale tracings, in the \\ construction of the Monastery of San Lorenzo del Escorial
}

\author{
$\underline{\text { P. Chías Navarro }}^{(*)}$ y T. Abad Balboa ${ }^{(*)}$
}

RESUMEN

El uso de diferentes tipos de dibujos, plantillas y modelos como elementos esenciales en las distintas fases de la construcción de los edificios históricos se ha investigado preferentemente para las tareas de cantería. El Monasterio del Escorial constituye un caso de estudio excepcional por la abundante documentación que se conserva sobre las condiciones, escrituras y libranzas de todas y cada una de las etapas y para los diferentes oficios, y por las descripciones de sus contemporáneos. El estudio del papel de las trazas y monteas en las decisiones de proyecto y en la construcción del edificio, así como su vinculación con los moldes y los modelos y con la documentación escrita durante la obra, aporta nuevas perspectivas a la construcción de las obras reales en España en los siglos XVI y XVII. Como resultado de la investigación, y procedente de varios documentos manuscritos, aportamos además material gráfico inédito sobre la construcción del Monasterio.

Palabras clave: Monasterio del Escorial; historia de la construcción; modelos; trazas; monteas; Sitios Reales; siglo XVI; siglo XVII.

\section{ABSTRACT}

Researches on architectural drawings, scale models, and full scale tracings, focus mainly on their application to particular examples of masonry. The Monastery of El Escorial becomes an outstanding case study because of the abundant existing documentation about the working conditions and procedures, and about deeds and orders of payment, which relate to each stage of the construction, and to every job. During the whole construction, models, drawings and full scale drawings played an essential rôle in order to come to a decision about a design or a building method. The setting-up of the interrelations between the written documents and the drawings that were produced along the construction process, provides a new perspective to the construction of the Spanish Royal Sites along the 16th and 17th centuries. As another result, we include some unpublished drawings.

Keywords: Monastery of El Escorial; construction history; scale models; architectural drawings; full-scale tracings; Royal Sites; $16^{\text {th }}$ century; $17^{\text {th }}$ century.

(*) Universidad de Alcalá, Alcalá de Henares (Madrid, España).

Persona de contacto/Corresponding author: pilar.chias@uah.es (P. Chías Navarro).

ORCID: http://orcid.org/oooo-0001-6686-8820 (P. Chías Navarro); http://orcid.org/oooo-0oo1-9225-0709 (T. Abad Balboa)

Cómo citar este artículo/Citation: P. Chías Navarro, T. Abad Balboa (2017). Modelos, plantillas, trazas y monteas en los contratos para la construcción del Monasterio de San Lorenzo del Escorial. Informes de la Construcción, 69(547): e219, doi: http://dx.doi. org/10.3989/id55077.

Copyright: (C) 2017 CSIC. Licencia / License: Salvo indicación contraria, todos los contenidos de la edición electrónica de Informes de la Construcción se distribuyen bajo una licencia de uso y distribución Creative Commons Attribution License (CC BY) Spain 3.o. 


\section{INTRODUCCIÓN, OBJETIVOS Y ANTECEDENTES}

La importancia que Felipe II diera a las trazas y los modelos durante la construcción del Escorial se manifestó tempranamente cuando en 1561 solicitó al general de los jerónimos algunas trazas de sus monasterios que pudieran servir para definir su traza universal: "holgaría que hiciereis traer algunas trazas de los mejores monasterios, para que por ellas [...] se pueda tomar la que fuere más conveniente para San Lorenzo» (1).

Entre las competencias que el rey incluyó en el nombramiento de Juan Bautista de Toledo como su arquitecto, figuraba que «como tal nos hayáis de servir y sirváis en hacer las trazas y modelos que os mandásemos, en todas nuestras obras, edificios y otras cosas dependientes de dicho oficio de arquitecto». La realización de trazas fue también una de las obligaciones de los aparejadores de la obra.

El uso de distintos tipos de dibujo, y el recurso a los modelos y los moldes, fue habitual a lo largo del desarrollo de la obra. $\mathrm{Su}$ carácter complementario quedaría claramente reflejado por Cabrera de Córdoba, pues en el proyecto todo se hizo «en carta de cuerpo entero, secciones o miembros, y después en modelo de toda la obra de madera, para que junta se viese mejor, y en su figura y compartimiento se enmendase lo que ello mismo mostrase ser necesario, procurando su mejora, por ser difícil acertar de la primera intención y disposición de tantas cosas» (2).

El objetivo y principal aportación original de esta investigación radica en establecer las relaciones entre los discursos gráficos -trazas, monteas y otros dibujos- y plásticos -modelos y moldes o plantillas-, y los documentos de obra, poniendo en evidencia su carácter complementario en los procesos de diseño y construcción. Al vincularlos de nuevo, como lo estuvieron en origen, y conocer su contexto, aquéllos recobran todo su sentido.

Otra aportación consiste en extender tales relaciones a todos los oficios, y no solamente a la cantería.

No menos importante es el descubrimiento y difusión de dibujos y textos inéditos, esenciales para avanzar en el conocimiento de la historia de la construcción de las obras reales.

El periodo de estudio abarca desde el replanteo hasta la conclusión de las obras a mediados del XVII; excluye, por tanto, la reconstrucción y evolución del edificio tras el devastador incendio de 1671.

La bibliografía existente sobre el Monasterio es muy abundante, por lo que sólo se citan aquellos textos generales que se centran en temas relacionados con su construcción, y a los levantamientos más recientes (3) (4). También se incluyen referencias sobre el uso de trazas y monteas en el Renacimiento y el Barroco.

Respecto a los modelos, remitimos al Catálogo de la exposición celebrada en el Palazzo Grassi de Venecia en 1994, al monográfico de Rassegna de 1987, y a los trabajos de Briggs, entre otros.

\section{DEFINICIONES Y FUENTES}

Los dibujos relacionados con la construcción arquitectónica son muy variados; obedeciendo a su finalidad, «algunos iban destinados al patrón, otros eran el resultado de la llegada del arquitecto a soluciones de diseño, otros eran dibujos de trabajo para ser consultados por los albañiles durante las obras. En la primera categoría podríamos citar grandes planos y alzados de presentación, dibujos cuidadosamente hechos [...] A la segunda categoría pertenecen planos esquemáticos hechos rápidamente por el arquitecto para ver el posible aspecto de algo. La tercera categoría es la más rica [...] el 'plano clave', sobre cuya base se ponía en correlación todas las partes [... y] los dibujos de tamaño natural o los detalles escultóricos» (5).

En esta investigación proponemos una nueva tipificación, en la que un primer grupo de dibujos integra a los que aportan una imagen idealizada o propagandística del edificio, que, partiendo de los Diseños de Herrera derivaron en numerosas versiones (6).

Otro grupo lo constituyen los croquis que describen algunos aspectos del entorno, entre los que destacan los de Francisco de Mora (7).

Otros definen el ceremonial y han sido atribuidos al taller de tracistas del Alcázar, como los que se intercalan en las Memorias de fray Juan de San Jerónimo (8), asociados a los ritos funerarios (Figura 1).

Carducho ya destacó el interés del rey por sistematizar tales rituales, pues guardaba en el Alcázar «las trazas, plantas y relaciones de las procesiones como las del Corpus [...] Las trazas y sus relaciones con los Túmulos que se han hecho en diferentes honras de Reyes [...] Las trazas de los juramentos de Príncipes [...] De los entierros, de su acompañamiento y ceremonias» (9).

No se ha conservado la traza general de Juan Bautista de Toledo que definía el edificio en su conjunto, ni el dibujo de la postura que debía tener la casa en el lugar elegido por el rey, pero queda una serie de dibujos a diversas escalas que definen partes del edificio. Las trazas constituyen, pues, los dibujos que permiten la definición formal y métrica de los elementos arquitectónicos y sus despieces, para obtener después las plantillas y otros instrumentos necesarios para su construcción (Figura 2).

En el Monasterio el uso de trazas no se limitó a los oficios de cantería, sino que se extendió a otros como la carpintería y la rejería. Su importancia se deduce de la existencia de la Casa de las Trazas en el Escorial y del Cubo de las Trazas del Alcázar, donde «están puestos estantes de madera de nogal tallados de medio relieve, y dorados sus perfiles, en que están las trazas, y papeles tocantes al oficio de Trazador, que se dedicó desde sus principios [...] para este efecto, y en él se demuestran las trazas de la gran fábrica de S. Lorenzo el Real» (10).

De los numerosísimos dibujos que se hicieron durante la obra y que desaparecieron, desgastados por el uso y tras el incendio del Alcázar de 1734, apenas han sobrevivido los catalogados por López Serrano (11) y los escasos publicados por otros autores -Bustamante, Marías, Moleón. Los que aún inéditos aportamos en el presente estudio, se insertan entre los documentos de obra. 


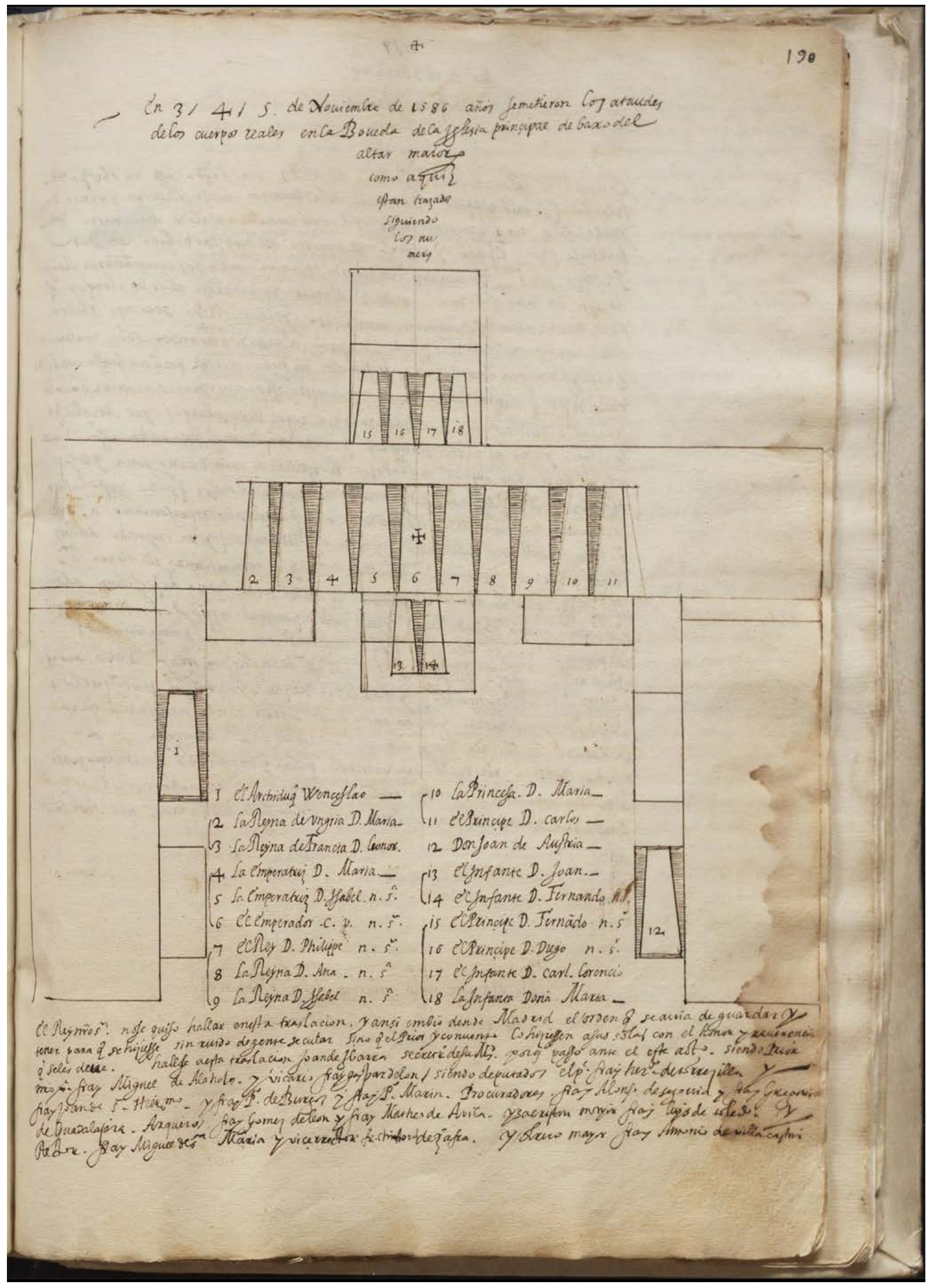

Figura 1. Taller de tracistas del Alcázar, 1586: Traza que detalla el lugar que debe ocupar cada ataúd en la bóveda bajo el altar mayor del Monasterio. Manuscrito de fray Juan de San Jerónimo, fo $190 \mathrm{r}$. 


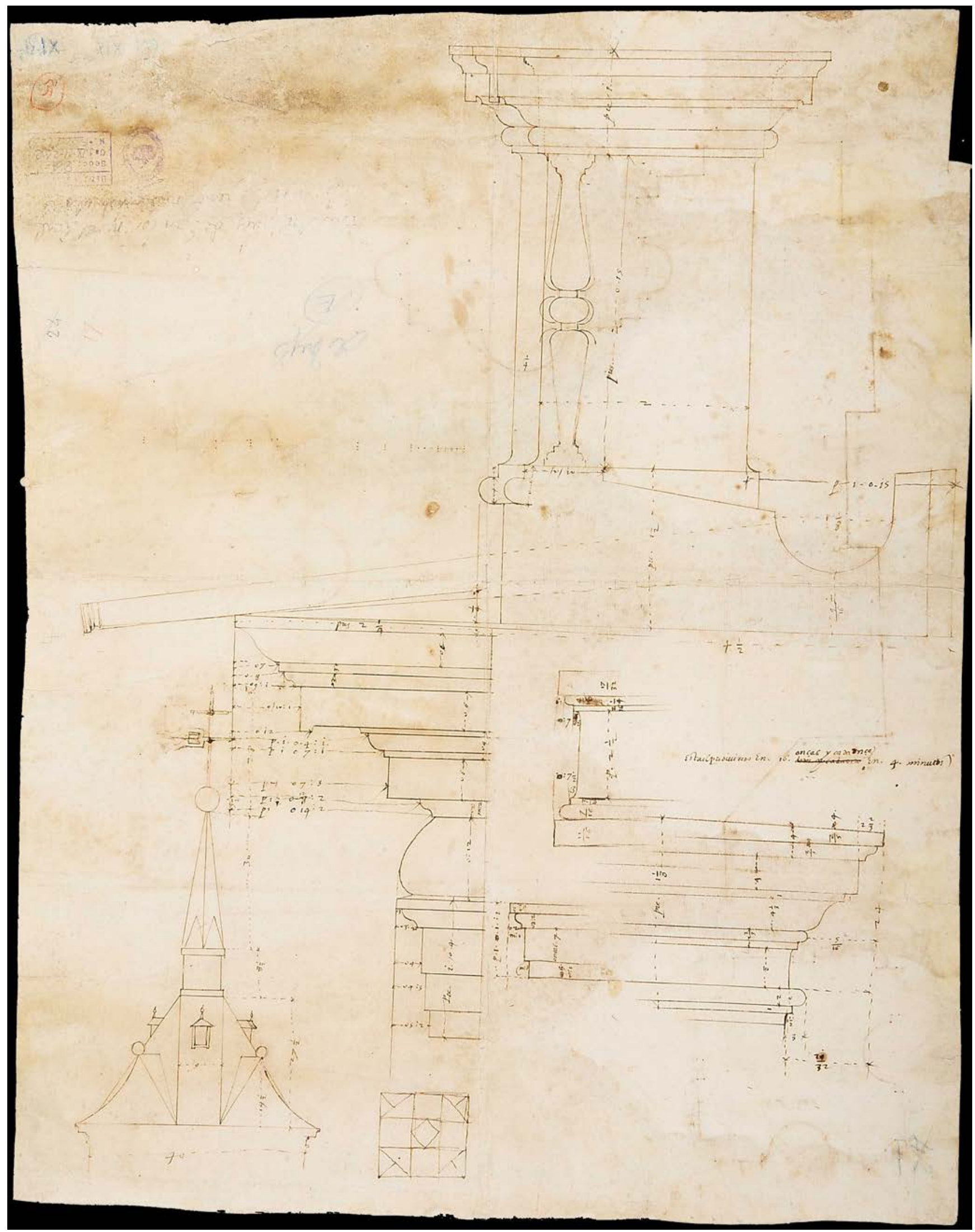

Figura 2. Juan de Herrera, 1569-1572: Traza del perfil del entablamento jónico, desagüe y balaustre del patio de los Evangelistas, chapitel de la Torre del Prior, croquis de sus tejados y molduras de la cornisa. BPR, Sign.IX/M/242/1-23.

Hemos excluido los dibujos de las soluciones que se propusieron durante el proceso de diseño de la fachada principal (12) (13) (14), o de la controvertida iglesia (15) (16), porque han sido ampliamente debatidos en otro lugar.
Las monteas constituyen otro grupo diferente: son dibujos a tamaño natural realizados sobre suelos y paredes en las últimas fases de concreción del proyecto. Definen con precisión las piezas que conforman cada elemento y su disposición, y 
permiten controlar mejor la ejecución al evitar los errores que introduciría el cambio de escala (17), demostrando la utilidad de la geometría y el valor de los procedimientos gráficos (18). En la documentación también aparece el término montea con los significados de alzado o elevación y como perfil.

Y se sabe que el tratado de Vandelvira era conocido por los artífices del Escorial (19), pues la pericia de sus canteros fue tal que llegarían a escribir un breve tratado de estereotomía, hoy perdido (20).

Además de los dibujos se realizaron modelos o maquetas del conjunto y de las partes, que facilitaron la toma de decisiones y la elección entre soluciones alternativas siguiendo una práctica habitual en la época. Sobre su uso en el Monasterio reflexionaba fray José de Sigüenza: «Esto de los modelos es tan importante en las fábricas que oso afirmar debérselas en ésta el todo, de salir tan acertada sin remiendos ni tachas, y si algunas tiene, nacieron de haberse mudado los modelos o las trazas, o no haberse hecho. Juan Bautista de Toledo [...] hizo modelo general, de madera aunque en forma harto pequeña, para toda la planta y montea, que llaman Genografía y Sgenografía. Alteró aquello en muchas partes [...] su discípulo Juan de Herrera, aunque sin daño y aun, al parecer de muchos, con perfección de la fábrica. Al tiempo de ejecutar la traza de iglesia que trajo Pachote, también se alteraron algunas cosas y se hizo un modelo de madera en mucha mayor cantidad, como se ve ahora en estos desvanes guardado; y para otras cien cosas se han hecho otros muchos, como para algunos ingenios y máquinas, y para estas sillas [del coro] tan acertadas. Allí se ven y se enmiendan los yerros sin daño, que después o no tendrían remedio o serían muy costosos, y allí se perfecciona con mayor certeza lo que no estaba tan cabal» (21). Durante la obra se hicieron modelos que afectaron a numerosos oficios, y que eran sometidos a la aprobación del rey.

Una anécdota que aclara el uso y conocimiento que se tenía de los modelos, refiere que al rey no había gustado la solución de la iglesia de Juan Bautista y que por ello había pedido opinión a Italia: «vemos en este edificio remates como aquellos que Sangallo situó en el modelo vaticano, órdenes superpuestos, cubos, elevadas pirámides, bolas terminales, frontones extendidos, toda una variada geometría que Juan Bautista debió incorporar a su desaparecido modelo» (22).

Los modelos de la obra del Monasterio no se han conservado, pues, colocados bajo las cubiertas, sucumbieron en el incendio de 1671. Pero quedan abundantes noticias en reales cédulas desde 1562, y en otros documentos que relacionan dibujos y modelos en las diferentes fases de la construcción.

Finalmente, el uso de moldes y plantillas conformados a partir de las monteas está profusamente documentado en los contratos de obra. Este aspecto de la construcción del Monasterio resulta particularmente interesante porque no ha sido estudiado hasta ahora.

La documentación que se conserva es muy extensa y se custodia fundamentalmente en el Archivo de la Biblioteca del Monasterio del Escorial (en adelante, RBME), el Archivo y la Biblioteca del Palacio Real (AGP y BPR, respectivamente), el
Archivo General de Simancas (AGS), el Archivo Histórico Nacional (AHN), los Archivos Zabálburu (AZ), del Instituto de Valencia de Don Juan (AIVDJ), y Municipal de San Lorenzo.

\section{La documentación que hemos manejado abarca:}

- Descripciones de testigos directos de la construcción, cronistas e historiadores de la Orden, que aportan la visión del entorno cortesano y de la congregación, como fray Juan de San Jerónimo (23), fray Antonio de Villacastín (24) y fray José de Sigüenza, quien dibujó un pequeño primer esquema general del cuadro ${ }^{1}$ que relaciona claramente el todo y las partes, reflejando el programa y el orden en la disposición de los cuartos²: "aunque los perfiles y la planta general, en lo que toca al cuadro de toda la casa, fue siempre el mismo, en lo demás ha habido grande mudanza [...] Ésta es así en común la primera planta del edificio que trazó Juan Bautista, que hace poca diferencia de la de ahora». Y continúa, siguiendo a Vitrubio, «uno de los primores grandes que tiene esta fábrica es ver cómo se imitan todas su partes y cuán una es en todas ellas» (25).

- Las cartas entre quienes actuaban de parte del rey y los representantes de la congregación.

- Los contratos de obras con sus condiciones detalladas y los plazos a los que se obligaban los destajeros, firmados por los principales deudores y sus fiadores ante testigos y el secretario.

- Las actas de las mediciones y las libranzas de pago, que comprobadas por los aparejadores de cantería, albañilería y carpintería, habían de ser aceptadas por el obrero mayor fray Antonio de Villacastín.

Como hemos comentado, algunos de estos documentos incluyen pequeños croquis que aclaran y definen alguna parte del texto, y que permanecen inéditos (Figura 3).

\section{EL MARCO NORMATIVO: ÓRDENES E INSTRUCCIONES}

Los contratos de las obras reales no escaparon al afán sistematizador del rey, quien en El Escorial se adelantó en un año a sus primeras Instrucciones generales de Obras Reales (26).

El 15 de abril de 1562 se dictó una primera Instrucción para dar comienzo a la obra estableciendo las figuras de contador, veedor y pagador por la parte del rey, y los que habían de actuar como procurador y proveedor por parte de la congregación. Contador y procurador debían llevar libros de gastos parejos.

Siguió la Instrucción para lo tocante al gobierno y ejecución de la fábrica fechada el 15 de agosto de 1563, que era una reelaboración de las anteriores y definía el empleo de los materiales y la obligación de los aparejadores de dar a la congregación una copia en limpio de todas las trazas (27).

Una tercera Instrucción del 12 de septiembre de 1569 fue una revisión necesaria ante la creciente complejidad de la obra y la insubordinación de los aparejadores que se negaban a entregar las trazas, e incluso las alteraban sin consentimiento del rey (28).

\footnotetext{
Planta general del edificio principal.

${ }^{2}$ En los contratos de obra suele significar una parte extensa del edificio.
} 

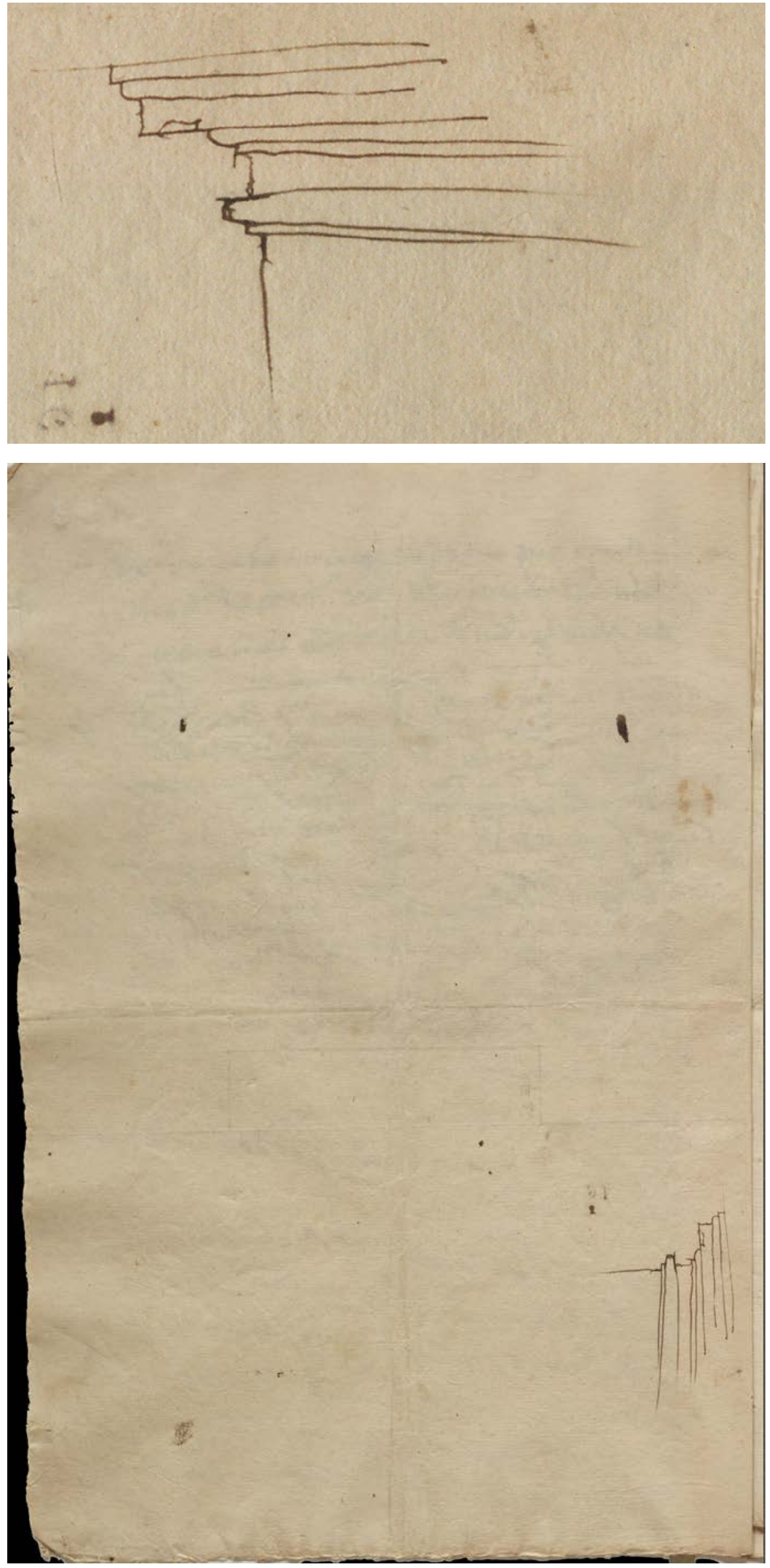

Figura 3. Traza de las molduras y el entablamento del patio, incluida en el concierto para labrar «uno de los pórticos menores en el cuarto de la Reina», 1578. RBME VI-18, f $^{\circ} 3 \mathrm{v}$. Página completa y detalle. 
La cuarta, de 22 de octubre de 1572, se basó en un estudio de Herrera para reorganizar la obra, constando expresamente que se consultara al rey antes de «mudar alguna de las cosas que por las dichas trazas tenemos ordenadas» (29).

Finalmente, las órdenes e instrucciones -dadas para regular aspectos concretos como la carretería o los tejares- menudearon para solucionar problemas urgentes en la obra. Tal fue el caso de la Orden que se dio a los padres prior y vicario y Joan Baptista de Toledo el 8 de marzo de 1565, en la que el rey repartió y reorganizó el trabajo en vista de los desencuentros entre arquitecto y congregación. Esta Orden, particularmente importante, supuso la aprobación de la traza general definitiva a la vez que dividía de facto los trabajos entre Juan Bautista y sus aparejadores -Escalante y Cortézubi-, y la congregación y los suyos - Tolosa y Gaspar de Vega (30).

\section{LA GESTIÓN DE LA OBRA}

La gestión siguió unos procedimientos muy rigurosos que sólo se alteraban en casos de trabajos singulares o especialmente delicados.

Cada ingreso debía quedar registrado como un asiento en los libros del contador y veedor, "y cuando se sacare el dinero se asiente clara y distintamente para qué cosas y efectos se saca». También el tenedor de materiales debía registrar en un libro «en que asiente con días, mes y año los materiales que recibiere, poniendo la cantidad peso y medida de lo que se le entregare, y apartada y districtamente (sic) de por sí cada género de materiales» (31).

Al principio se pagaron trabajos a jornal, pero pronto se pasó a contratar destajos parciales con la excepción de los cimientos, «que se harán a jornal hasta que afloren a la superficie»; la medida sirvió para acelerar las obras.

Las condiciones de cada destajo se redactaban previamente detallando los trabajos, los materiales a emplear y las dimensiones que tenía que tener cada elemento «conforme a la planta y montea que para ello está hecha». Los destajeros interesados «hacían posturas ${ }^{3} »$.

Por ejemplo, la traza de la Figura 4 acompaña a las «Condiciones con las cuales se han de ahondar los caños de la bodega [...] ahondando tierra y piedra de siete pies de ancho todo derecho a cordel por el medio de la bodega hasta llegar desde la puerta al derecho y cuadrado del caño postrero [...] luego han de labrar las paredes a cordel y plomo de piedra y cal, de grueso de dos pies a lo menos dando al caño al principio dos pies de ancho y pie y medio de hondo [...] y suban las paredes de pie derecho conforme a los caños dichos que queden a un alto desde el suelo, y bien enrajados y revocados y ripiados con cal y piedra: han de hacer luego bóvedas de ladrillo para cubrir la dicha madre [...] también han de dejar las bóvedas descimbradas, revocadas y raidas [...] y los suelos de la dicha madre han de quedar llanos a cordel, labrando el dicho suelo de cal y piedra [...] para lo cual labrar les han de dar doce picas y seis azadones, y espuertas para sacar la tierra, y madera para andamios y cimbras; los clavos los que fueren menester, y almádenos dos y seis cuñas, y dos palancas y dos palas de hierro, y la piedra y cal como se suele dar en los otros destajos: la piedra se entiende repartido tosco; este escrito le vieron los aparejadores de la obra de San Lorenzo el Real y la tasaron en ciento y treinta ducados y dijeron poderse hacer por los mrs. susodichos y así lo firmaron con sus nombres. Pedro de Tolosa. Lucas de Escalante. Francisco Gutiérrez. Visto por Vicente Obregón y Juan Martín y Esteban Frontino las condiciones y tasa que se hizo de la dicha obra, dicen que la harán conforme a las dichas condiciones por ciento y treinta ducados» (32) (Figura 4).

A los destajeros se les suministaban por cuenta del rey los materiales puestos en la obra «en parte donde puedan llegar las carretas», las mezclas aglomerantes y las herramientas, así como todo lo necesario para hacer las cimbras e ingenios necesarios, que, una vez terminado el destajo, debían ser desmontadas y trasladadas donde se les indicara. Corría por cuenta del destajero la «costa de oficiales y peones y no le han de dar nada por ello» (33). También se hacía una valoración previa o tanteo de lo que podía costar cada parte.

Como cautela previa a la adjudicación de los destajos, el mejor proceder para el rey era que los destajeros «tanteasen y mirasen con gran atención lo que según las condiciones y obra que se ha de hacer [...] y que no se dé ningún destajo sin traer primero hecha esta diligencia, y que después de tenerla hecha, y labradas las muestras de canteria o de carpinteria que hubieren de seguir los destajeros, propongan entre muy buenos oficiales conocidos los destajos que se han de dar, y que tomándolos en precios convenibles se les den por ellos, y no se pongan en pregón como se suele hacer, porque encargándose dello buenos oficiales en honestos precios y han de hacerlo muy bien y conforme a las muestras y traza» (34).

Una vez acabadas las obras eran medidas y tasadas por los aparejadores, y se comparaban con las aportadas por el destajero. En las condiciones también quedaba detallado cómo habían de medirse los diferentes elementos. Por ejemplo, en la escritura que otorga el destajo de la sacristía principal se especifica que «háse de medir este dicho atajo ${ }^{4}$ desde los vivos de las columnas adentro dejando fuera las salidas de las molduras de basas y capiteles y cornisas hasta en alto de la cornisa y de allí arriba a lo que hubiere de grueso» (35).

Después se aplicaban los precios convenidos y contenidos en la adjudicación de los destajos, descontando los pagos realizados a cuenta. $Y$ «si alguna cosa particular o cosas se les añadiere, que hagan más o menos de lo que muestra la montea, que le sea pagado o quitado respecto de la estimación de las otras particularidades de la dicha obra» (36).

Un ejemplo muy detallado de valoración aparece en la «Estima de la cantería de uno de los claustros chicos», que considera lo que cuesta sacar en la cantera y desbastar cada pieza, sumándose después los elementos que con ellas se componen y los jornales que se han empleado en la colocación: «Los ocho arcos que van dentro del claustro se harán en días 176, que a 4 reales el día montan Reales 704». Además se advertía que «quien tomare el destajo haga a su costa los andamios, dándosele madera y clavazón para ellos, y así mismo ha de hacer los ingenios de subir las piedras a su costa, como le fueren ordenados» (37).

\footnotetext{
3 Tomar parte como licitador en una puja o subasta.

4 Muro que separa dos capillas contiguas.
} 


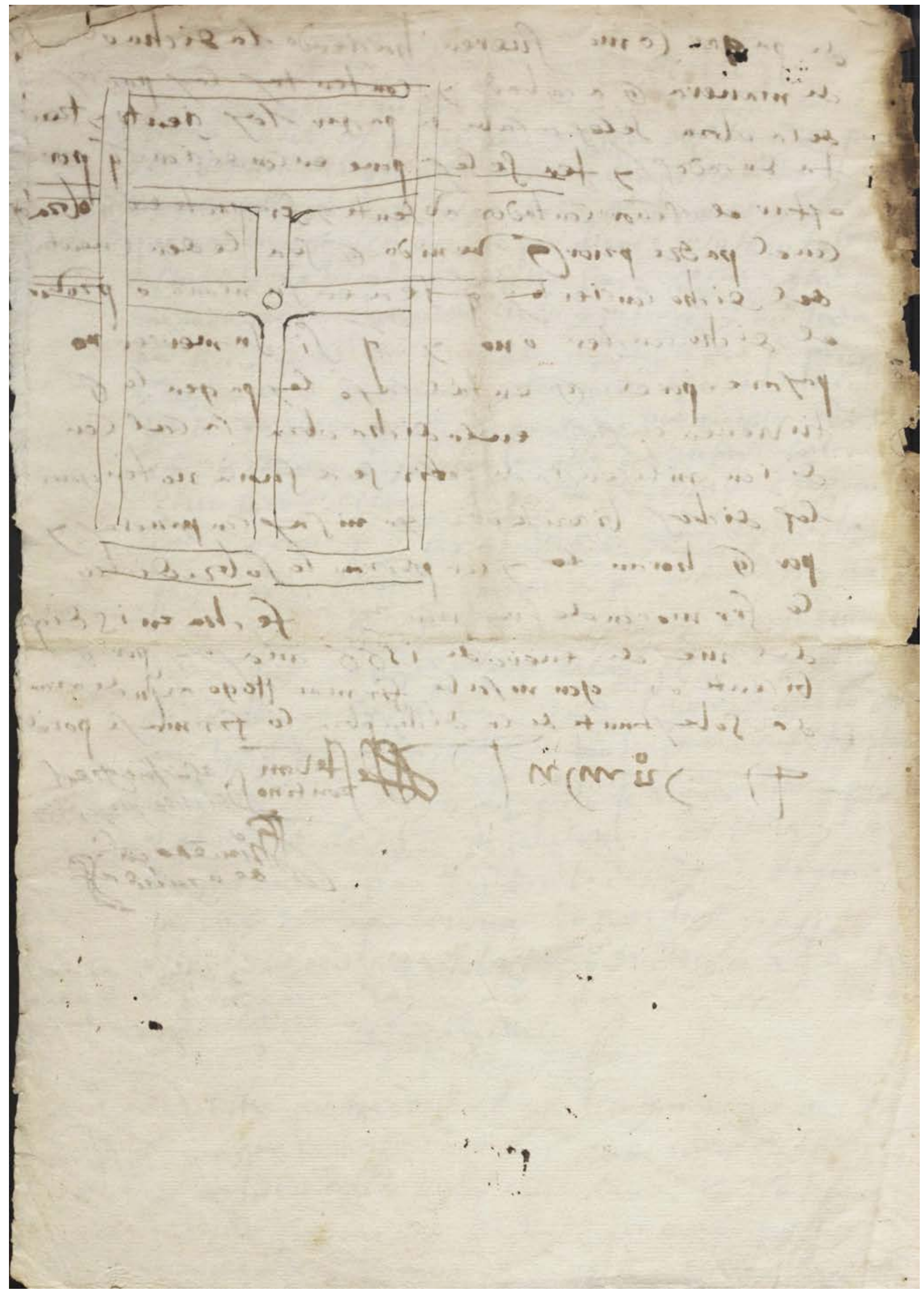

Figura 4. Traza incluida en las «Condiciones según las cuales se han de ahondar y labrar los caños de la bodega». RBME I-64,fo 2 v. 
El finiquito lo firmaba Villacastín, «dando por buena la obra».

Según las adiciones de 1573 a la Carta de Fundación del Monasterio, toda la documentación de la obra debía duplicarse, incluyendo las trazas, pues el rey enviaba una copia al Archivo de Simancas (38), otra quedaba en el Monasterio y, a veces, solicitaba una más para su uso personal.

\section{TRAZAS Y MONTEAS EN LA DOCUMENTACIÓN DE LA OBRA}

La desaparecida traza universal pudo consistir en una serie de dibujos del conjunto - plantas, alzados, secciones- que se reflejarían inmediatamente en un modelo o maqueta (39), como efectivamente se desprende de la correspondencia en la que Hoyo informaba al rey sobre la marcha de las obras (40).

Desde el principio el rey solicitó otras opiniones que alejaron la coherencia de la traza inicial de Juan Bautista proponiendo un mosaico de soluciones: «Parece al Marqués [de Cortes] y al Conde [de Chinchón] que se haga la iglesia cuadrada de la traza de Pachote. El claustro grande de la traza de Juan Bautista. La entrada de la iglesia al modo de la traza de Juan Bautista. El aposento de su Majestad y oficinas como está. En lugar de las oficinas, que están hechas para servicio de los frailes, jardín privado. Todo lo restante del monasterio procurar repartirlo como mejor convenga, tomando algo de lo general de la traza de Gaspar de Vega, porque además de que será más al propósito de los frailes lo que se ensanchase, vendrá más a proporción con la anchura que tiene la traza de Juan Bautista, de manera que el monasterio y todos sus servicios queden debajo de un cuadro» (41). Esta política rigió la construcción hasta el final, lo que implicó demoler o modificar algunos elementos ya construidos.

La congregación manifestó la utilidad de tal traza de conjunto «para que entendamos si la obra que se hace es conforme a ella», reclamando el modelo que estaba en el Alcázar para tenerlo a pie de obra, ya que "para lo que tocare a puertas y ventanas y otras cosas, será menester mirar en él cada hora» (42). También hubo que ampliar algunos dibujos como la traza de la Galería de Convalecientes «para poner la torre y corredores del sol de la enfermería se añadirá el papel que fuere menester» (43).

Desde mayo de 1564 Juan Bautista fue dibujando también las trazas parciales de toda el área conventual; la más antigua conservada -RBP, Sign.IX/M/242/1-22- es la de la Torre de la Botica (44). Aquéllas fueron muy criticadas por el prior, como se desprende de una carta que envió a Hoyo en la que, respecto al aposento del rey, afirmaba: «yo vi el rasguño y le tuve en mis manos y estaba tan cifrado de cuentas y tan menudo de puntos que apenas yo le podía ver, y él tenía guardado y lo mostraba y verse ha, a cuya culpa es el yerro que aunque Juan Bautista diga que para eso teníamos acá la traza, está sin poner en ella número de grueso de paredes ni piezas, y si dijere que tenía pitipié es verdad que lo tiene, pero es tan chiquitito que no hay con qué fiar de él para sacar medida cierta para hacer ninguna cosa por él si no es de poco mas o menos» (45). Estos reproches obligaron al arquitecto a actualizar sus propios dibujos, pues hizo «sacar la traza del palacio de Su magd. de lo que está hecho al presente, con líneas negras, y en- cima de ella diseñé de puntos cómo había de ser, que es conforme a la traza universal que Su Magd. me mandó dar a los padres» (46).

La detección de errores entre las trazas y lo construido fue también frecuente, y se debió a causas diversas como los desacuerdos entre Juan Bautista y los ayudantes, que introdujeron discrepancias, descubiertas por el rey, en el número de ventanas del lienzo de la fachada meridional: «He mirado en la montea que trajisteis del costado del Mediodía que está errada, que como a la parte de los claustros hay 20 ventanas, desde la torre de la botica hasta la de enmedio donde ha de ser la iglesia de prestado, han puesto otras 20 desde esta torre de enmedio hasta la otra esquina, entre el Mediodía y el Levante, donde ha de ser la celda del prior, y en esta parte no han de ser sino 18 las ventanas, y no 20 y así en las plantas no hay sino 18» (47).

La elaboración de trazas no fue competencia exclusiva de Juan Bautista, como se desprende de la correspondencia entre el prior fray Juan de Huete -que era «muy entendido en cosas de trazas»- y el secretario. Éstas se hicieron a la misma escala que las del arquitecto: «Los rasguños para acrecentar refectorio y dormitorio de novicios y celdas para frailes, algunos tenemos hechos a diversos diseños. Tolosa ha hecho dos o tres y yo otros tantos, aunque no he tenido salud para sacarlos en punto que se puedan entender bien, porque están hechos al pitipié de la planta de Juan Bautista para que plicados sobre ella se entienda como en lo que ahora está edificado, [pues] no se hace ni ha de haber mudanza ni más extensión de sitio del cuadro de toda la casa que está definido desde el principio» (48).

También se hicieron trazas de las instalaciones, pues el 1 de julio de 1562 Hoyo comunicaba al rey que había solicitado al vicario «que hiciese un rasguño de cómo le parece que se deberían repartir las aguas en el monasterio: dice que habrá menester la planta baja, y entender la voluntad de V.M. de en qué partes será servido que haya fuentes y cómo se han de mostrar» (49). A principios de 1565 ya estaba hecho el plano general de la distribución de las aguas de la fábrica, pues el rey solicitó a Herrera que lo examinase y se lo explicara (50). Respecto al saneamiento, quedaron detalladas tanto las trazas generales como las de los distintos cuartos, y especialmente de las necesarias (Figura 5).

Otro grupo de trazas definía los detalles constructivos de los diferentes oficios, como consta en una carta enviada por el secretario al rey en agosto de 1565 en la que menciona el dibujo para el modelo de reja para los claustricos: «para las demás rejas de estos dos claustros hizo Juan Bautista el rasguño, y comunicado con los padres y los demás, acordado el cómo han de ser por todos, se quedó haciendo el modelo en palo y vendrá aquí para hacerse en hierro; y en estando acabado, se enviará a Pero González de Escalante para que las haga hacer en Vizcaya». A lo que el rey apostilló: "para esto dad mucha prisa al modelo de hierro» (51).

También se hicieron monteas de las cubiertas para el oficio de carpintería y para los pizarreros.

Las trazas estaban frecuentemente acotadas - «se harán guardando los números que están señalados por ellas»-, y anotadas con datos en correspondencia con las condiciones de los destajos (Figura 6). 


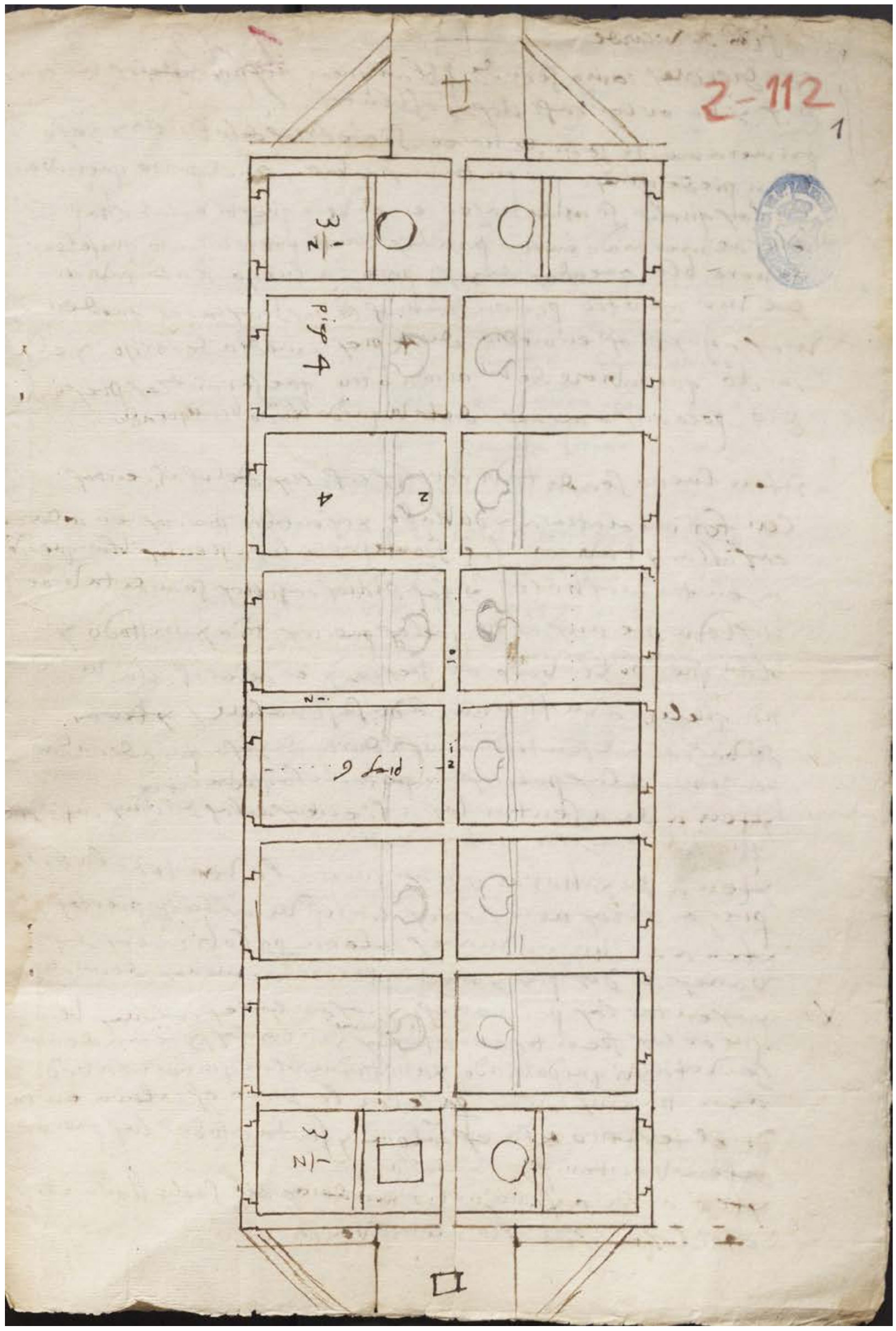

Figura 5. Traza de las necesarias incluida en las «Condiciones para blanquear las piezas de las necesarias y hacer las casillas

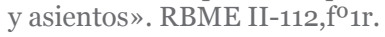




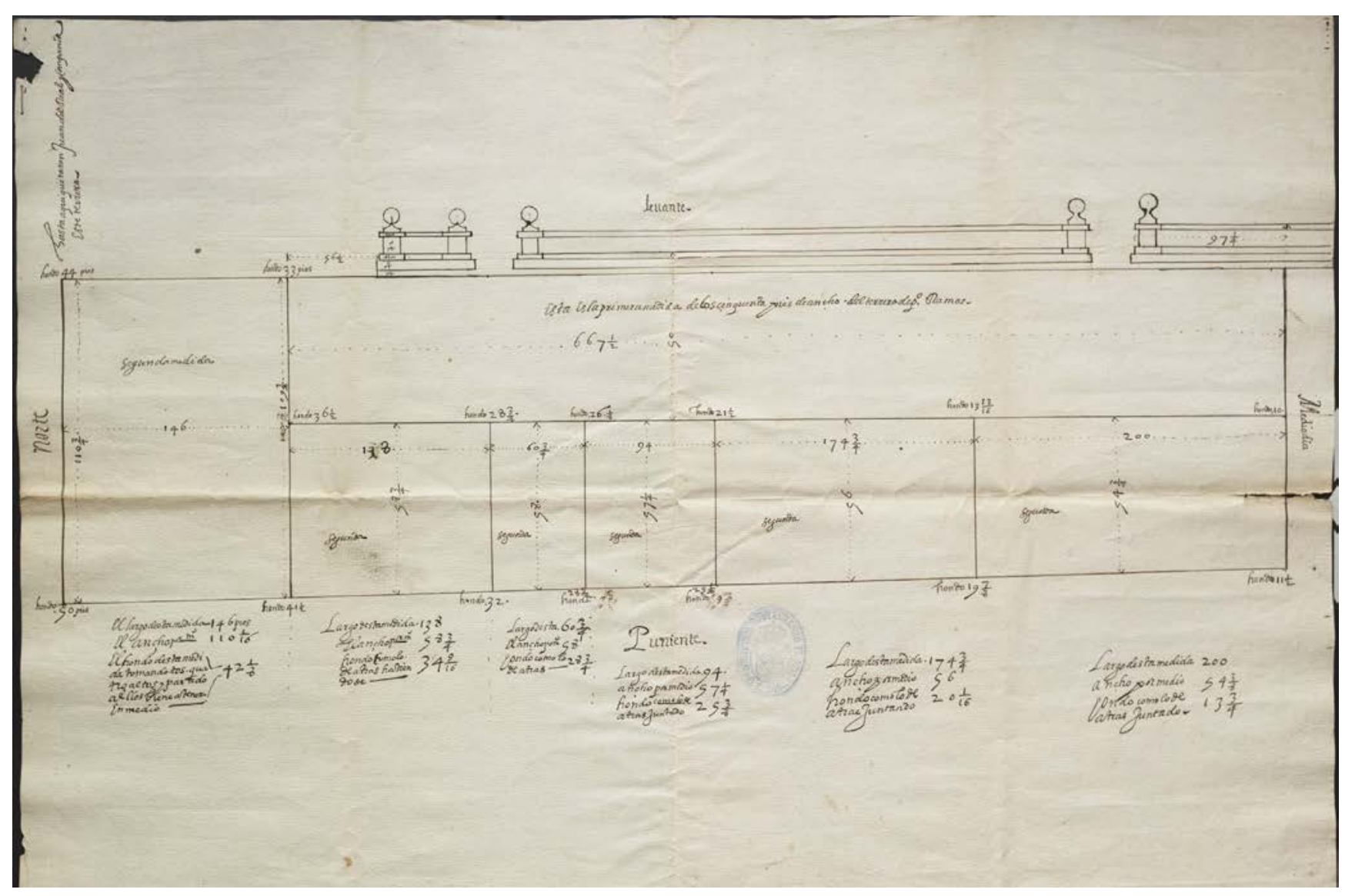

Figura 6. Traza y medición de lo que queda por quitar del terreno delante de la Lonja. RBME XII-24, $\mathrm{fo}^{\mathrm{f}} 25$.

El uso combinado de monteas y trazas es muy frecuente en las condiciones dadas a los albañiles para la bóveda del Capítulo: «las capillas se han de hacer de ladrillo y yeso conforme a una planta y montea dada» por Tolosa, añadiéndose que «se le han de dar el punto de la bóveda y lunetas trazado en el suelo y que el dicho oficial haga los plantones y cimbras a su costa, dándole materiales para ello según dicho es» (52).

Hemos fechado a finales de noviembre de 1564 las monteas identificadas por López Mozo (53) en las bóvedas de Platerías, según figura en la Memoria de Juan Bautista: «torné a recorrer todas las medidas y hacerlas señalar con los cinceles y clavos y números y almagra encima y en los lados de las piedras de los muros, porque las aguas de los días pasados nos las habían quitado» (54). Existe un segundo grupo en la truncada escalera del Prior, que se concluyó en 1574.

\section{MODELOS Y MOLDES EN LOS DOCUMENTOS Y LOS CONTRATOS DE OBRA}

Existen abundantes noticias de los modelos que sirvieron para entender las soluciones adoptadas para el conjunto o las partes, resultando imprescindibles en la toma de decisiones durante la construcción. Las trazas siempre fueron previas, y el conjunto de estos documentos trasluce la forma de trabajar en la obra.

Una real cédula emitida el 2 de febrero de 1562 ya menciona «la traza y modelo que está haciendo» (55), y en abril el secretario Hoyo comunicaba al rey que «Juan Bautista, en respuesta a lo que V.M. me mandó, me dijo que acabaría ayer tarde o esta mañana de umbrar (sic) lo que faltaba de la plan- ta baja del monasterio, y que entendería luego en buscar el recaudo necesario para que se pueda comenzar el modelo, y yo le ofrecí que le haría dar las maderas que fuesen menester» $(56)$.

A finales de mayo el rey urgía de nuevo al arquitecto: «para hacer bien el modelo es menester que tenga acabadas primero las plantas segunda y tercera, y así haréis que no alce la mano de ellas, porque conviene que las vea yo antes que llegue a ver el modelo por que no se hagan las cosas dos veces» (57). Trabajaba entonces en el modelo Jerónimo Gili con los carpinteros y entalladores Francisco Moratalla, Juan del Arco, y un artesano llamado el Portugués. A principios de febrero de 1563 este modelo ya estaba terminado (58), y hubo que desmontarlo y embalarlo para su traslado al Monasterio.

Los modelos parciales para decidir sobre soluciones de diversa autoría menudearon durante toda la obra; queda noticia de los correspondientes a los claustricos, el claustro principal, el muro de los nichos, la escalera principal -de la que también hizo un modelo Juan Bautista Castello Bergamasco-, la iglesia, el palacio, las cubiertas y chapiteles, el colegio y las «oficinas y todo lo demás que dentro del cuadro caben». Así, en una carta enviada por Juan Bautista a Hoyo, se lee: «Aquí envío a Jerónimo Gili, mi discípulo viejo, que lleva el modelo de los cantones de los claustros chicos hecho en dos maneras: la una como si hubiese de ser los corredores en bóveda, y la otra como si hubiese de ser de madera» (59).

Aparte del modelo de conjunto, el de la iglesia fue el más importante. Martín de Alciaga lo comenzó en 1573 basándose 

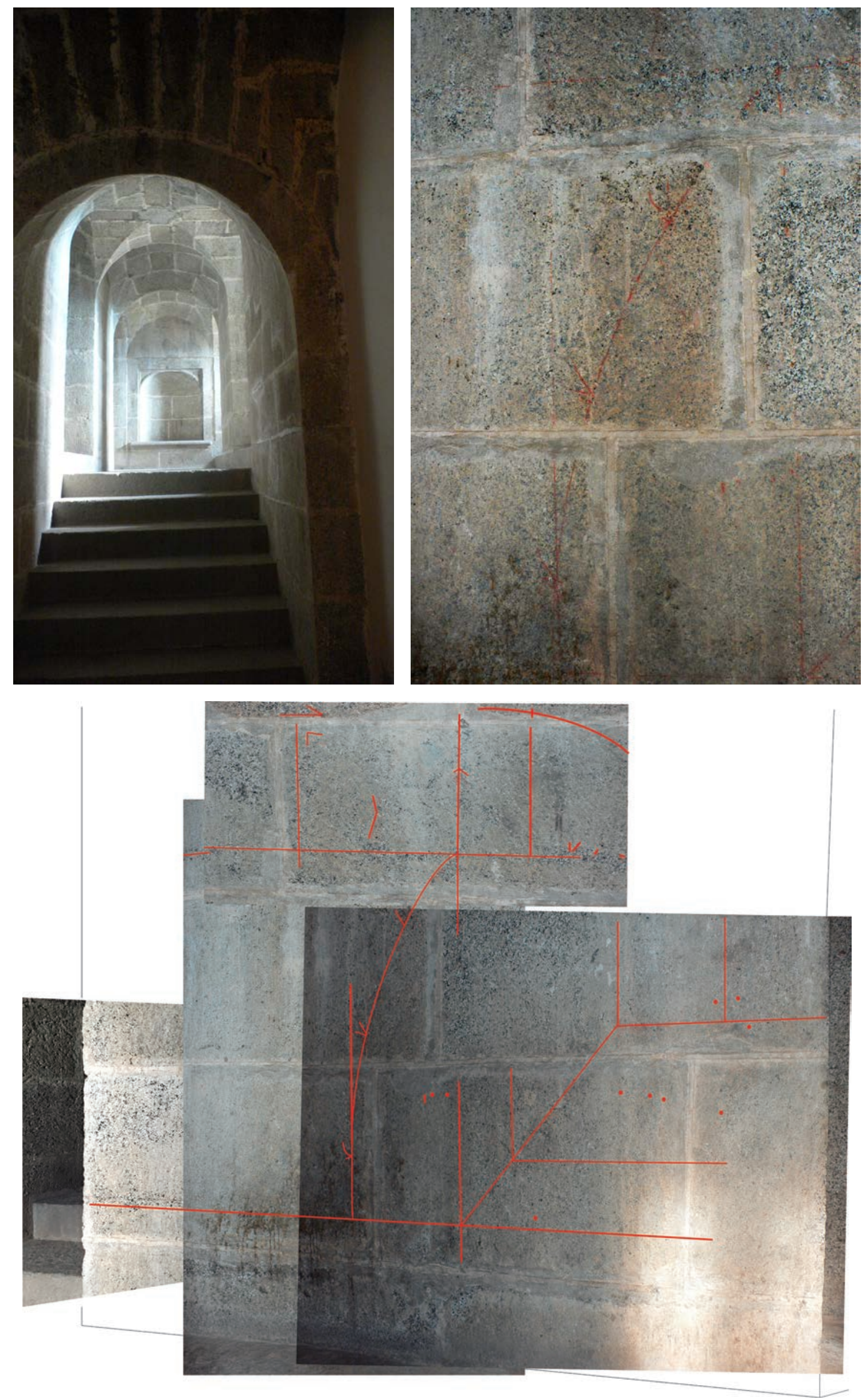

Figura 7. Monteas en los sótanos de Platerías. Bóvedas, detalle y restitución de las monteas conservadas en el lienzo norte. 
en trabajos anteriores sobre trazas de Diego de Alcántara, y tardó en tallarlo dos años (6o).

Aumentando de escala se hicieron también «modelillos» como el de la puerta de las cocinas, de las fajas y antepechos, de las cerraduras de las celdas, e incluso los ya comentados de las rejas.

Frecuentemente se recurría al modelo para definir soluciones constructivas; tal sucedió en la caja de la escalera principal y en los antepechos de las escaleras de bajada a la huerta, especificándose que «todas estas dichas piedras de los antepechos han de ir engrapadas y despiezadas según se ve por el modelo que para ello está hecho; los dichos engrapamientos han de ser con las mismas piedras para que no causen fealdad como se parece por el dicho modelo, guardando siempre sus buenas ligazones como en todo lo demás está dicho [...] para toda esta dicha obra se les dará a costa de su magd sus moldes uno de cada diferencia y un baivel y sus cerchas y si mas fueren necesarios los harán a su costa dándoles la madera para ellos o la hoja de lata» (61).

También se recurrió a muestras y a elementos ya construidos como referencia para otros nuevos, como con la moldura de los 30 pies que «se ha de labrar conforme a una que labró Aparicio de Marron» (62); con las tijeras, que «han de ir despiezadas como están trazadas en la muestra»; con el suelo alto sobre el refectorio, que habría de hacerse «conforme y tal como está hecho el suelo de sobre el dormitorio principal» (63); con los azulejos, que «han de ser conforme a las muestras que quedan en poder del padre Fray Antonio»; con el jaharrado de los atajos «conforme como a los que están hechos en el claustro» (64); o con «los caños vidriados con sus encajes de macho y hembra, del grandor y hechura que tiene un caño que está y tiene en su poder el padre fray Antonio de Villacastín por muestra y patrón de los dichos caños, los cuales son para las encañaduras del agua que se ha de traer» (65).

El uso de plantillas o moldes fue también habitual. Se proporcionaban por cuenta del rey, como consta en las condiciones de los destajos: «Hásele de dar al maestro que la tal obra tomare un baivel de cada cosa que fuere necesaria de las vueltas, y asimismo un molde de cada diferencia de molduras, esto a costa de S.M., quedando siempre los originales con las trazas en poder del dicho Lucas de Escalante, como aparejador de la partida y veedor en lo que toca al arte para que no haya alteración alguna; todos los demás moldes o plantas de hierro, y de otra cosa que hubiere necesidad el tal maestro, las hará a su costa» (66).

La primera noticia sobre el uso de una plantilla aparece el 5 de junio de 1564 cuando, sobre la controvertida moldura del talud de las fachadas sur y este, el prior Huete aseguraba a Hoyo que «yo entenderé luego en rascuñar una plantilla para tenerla hecha cuando los oficiales que V.m. señala vengan, para que la puedan ver y que ellos digan su parecer, y Tolosa hace también otra, que lo hace bien, y en lo que la moldura que está labrada si se ha de mudar no puede ser sino de mucha costa por estar labrado todo lo que es menester, que ha costado hartos dineros por ser mucha cantidad» (67).

Como práctica habitual en la labra de cantería, en noviembre de 1565 llevaba Herrera al Escorial los moldes para hacer los pedestales de los claustros chicos, que el rey había ordenado que se hiciese acompañando la traza del alzado interior -BPR Sign.IX/M/242/1-20-. Tres meses después, una «Memoria de la piedra y piezas que se manda sacar al presente para la obra del monasterio", incluía el compromiso de los canteros de sacar veinte piezas para los pedestales de los pilares rincones del claustro mayor «conforme a los contramoldes y galgas que se les dieren» (68). Y en las condiciones para hacer la bóveda del refectorio en marzo de 1570, figura que el aparejador Tolosa «le dará todas las formas y plantones necesarios para cruceros y perpiaños» (69).

Hay numerosos ejemplos en otros oficios como, por ejemplo, en la reja y el antepecho del coro de la iglesia de prestado que se hicieron «conforme a los modelos y patrones que se cortaron [de papel] a tijera de los balaustres bordones» (70).

\section{CONCLUSIONES}

La primera conclusión que se desprende de la investigación es lo moderno y estructurado que estaba el proceso de contratación, ejecución y liquidación de las obras reales en el siglo XVI.

Durante aquél las trazas no fueron competencia exclusiva del arquitecto ni del maestro mayor y, aunque se partió de una idea unitaria y se mantuvieron las dimensiones del cuadro y el programa, el proyecto evolucionó recogiendo sugerencias y pies forzados, y resultó muy diverso en sus soluciones parciales y de detalle.

La secuencia de trazas, modelos y monteas, estrechamente vinculados con los documentos escritos, evidencian el modo de trabajar en la obra. Además, este uso combinado de trazas, modelos, monteas y plantillas durante toda la construcción se generalizó a todos los oficios (Figura 7).

Finalmente, la posibilidad de consultar los documentos originales nos ha permitido descubrir dibujos hasta ahora inéditos y transcribir algunos fragmentos que reflejan claramente las relaciones entre lo gráfico, lo plástico, lo contratado y lo finalmente construido.

\section{AGRADECIMIENTOS}

A Patrimonio Nacional, a la Real Biblioteca del Monasterio y a la Comunidad Agustina por el apoyo prestado durante la realización de esta investigación.

\section{REFERENCIAS}

(1) Llaguno y Amírola, E. (1829). Noticias de los arquitectos y la arquitectura desde su restauración...ilustradas y acrecentadas con notas, adiciones y documentos, por D. Agustín Ceán Bermúdez, vol. II, pp. 81 y 227-231. Madrid: Imprenta Real.

(2) Cabrera de Cordova, L. (1619). Filipe Segundo Rey de España, Lib.VI, cap. XI. Madrid: Imp. Luis Sanchez. 
(3) Rabasa, E., et al. (2003). The external façade of the Monastery of El Escorial: Traces of a Process. In Proceedings of the First International Congress on Construction History (pp.1669-1677). Madrid: Instituto Juan de Herrera.

(4) López Mozo, A. (2008). Tres monteas escurialenses. Revista EGA, 13: 190-197.

(5) Kostof, S., et al. (1984). El arquitecto: historia de una profesión. Madrid: Cátedra.

(6) Chías, P. (2016). La iconografía del Monasterio de El Escorial: Tradición e innovación en cuatro siglos de imágenes impresas. Revista EGA, 28: 32-43, doi: http://dx.doi.org/10.4995/ega.2016.6046

(7) Chías, P., Abad, T. (2016). La transformación de la topografía y del paisaje en la construcción del Monasterio de El Escorial. Informes de la Construcción, 68(543): e159, doi: http://dx.doi.org/10.3989/ic.15.142

(8) San Jerónimo, J. de (posterior a 1591). Libro de memorias deste Monasterio de San Lorenzo El Real. RBME Mss.K-I-7,$\mathrm{fo}^{\mathrm{o}} 51 \mathrm{r}-52 \mathrm{r}$ y $190 \mathrm{r}$.

(9) Carducho, V. (1633). Diálogos de la pintura, Discurso Octavo, ff.153-154. Madrid: Imp. Francisco Martínez.

(10) Blasco Esquivias, B. (2013). Arquitectos y tracistas. El triunfo del Barroco en la Corte de los Austrias, pp. 105-110. Madrid: Centro de Estudios Europa Hispánica.

(11) López Serrano, M. (1944). Biblioteca de Palacio. Catálogo de Dibujos. I. Trazas de Juan de Herrera y sus seguidores para el Monasterio de El Escorial, Madrid: Patrimonio Nacional.

(12) Ruiz de Arcaute, A. (1936). Juan de Herrera, arquitecto de Felipe II, pp. 16 y 33. Madrid: Espasa-Calpe.

(13) Íñiguez Almech, F. (1965). Las Trazas del Monasterio de San Lorenzo de El Escorial, pp. 44-51 y 147-150. Madrid: Real Academia de Bellas Artes.

(14) Kubler, G. (1983). La obra del Escorial (1521-1706), pp.176-179. Madrid: Alianza.

(15) Bustamante García, A. (1994). La octava maravilla del mundo, pp. 36-52 y 128-129. Madrid: Alpuerto.

(16) Ortega Vidal, J. (2000). El Escorial: dibujo y lenguaje clásico, pp. 113-147. Madrid: Sociedad Estatal para la Conmemoración de los Centenarios de Felipe II y Carlos V.

(17) Calvo López, J. (2016). De la traza de montea a la geometría descriptiva. La doble proyección ortogonal en la ingeniería militar, de la Edad Media a la Ilustración. En Cámara, A. (ed.), El dibujante ingeniero al servicio de la monarquía hispánica. Siglos XVI al XVIII (pp. 45-67). Madrid: Fundación Juanelo Turriano.

(18) Bonet Correa, A. (1986). Ginés Martínez de Aranda, arquitecto y tratadista de Cerramiernos y arte de montea. En Ginés Martínez de Aranda, Cerramientos y trazas de montea (pp. 13-34). Madrid: CEHOPU.

(19) Rabasa, E., y López Mozo, A. (2011). El Escorial. Estereotomía de la piedra. En El Escorial: historia, arte, ciencia y matemáticas (pp. 149-180). Madrid: Ministerio de Educación.

(20) Bustamante, A., Marías, F. (1985). El Escorial y la cultura arquitectónica de su tiempo. En El Escorial en la Biblioteca Nacional. IV Centenario del Monasterio del Escorial (pp. 117-148). Madrid.

(21) Sigüenza, fray J. de (1605). Tercera parte de la Historia de la Orden de San Gerónimo, Discurso XII. RBME, Ms.8cII-22.

(22) Zuazo, S. (1964). Juan Bautista de Toledo y Juan de Herrera. En Sánchez Cantón, F. J., y Zuazo, S., Lecciones de El Escorial (pp. 37-67). Madrid: Taurus.

(23) San Jerónimo, J. de (posterior a 1591). Libro de memorias deste Monasterio de San Lorenzo El Real. RBME Mss.K-I-7,$\mathrm{fo}^{\mathrm{o}} 51 \mathrm{r}-52 \mathrm{r}$ y $190 \mathrm{or}$.

(24) Villacastín, A. de (1595). Memorias. RBME, Mss.f-IV-34.

(25) Sigüenza, fray J. de (1605). Tercera parte de la Historia de la Orden de San Gerónimo, Discursos I-IV y II-XII. RBME, Ms.8c-II-22.

(26) AGP,CR,II,ff.362-370.

(27) RBME I-21.

(28) RBME II-40.

(29) Zarco, J. (1985). Documentos para la historia del Monasterio de San Lorenzo el Real de El Escorial. III- Instrucciones de Felipe II para la fábrica y obra de San Lorenzo el Real. Madrid: Cimborrio.

(30) AGS, Junta de Obras y Bosques, Casas y Sitios Reales (en adelante OyB, CySR), leg.26o.

(31) AGS, OyB,Escorial,legs.5 y 6.

(32) RBME I-64,ff.1r-2v.

(33) RBME II-45.

(34) IVDJ Envío 61(1),ff.327-330.

(35) RBME III-5.

(36) AGS,OyB,Escorial,leg.1.

(37) AGS,OyB,Escorial,leg.1.

(38) RBME III-55.

(39) Martín González, J. J. (1986). Formas de representación en la arquitecura clasicista española del siglo XVI. En Herrera y el Clasicismo (pp. 21-32). Valladolid: Junta de Castilla y León.

(40) IVDJ Envío 61(1),ff.31-32.

(41) AGS,OyB,Escorial,leg.2.

(42) Modino de Lucas, M. (1985). Los priores de la construcción del monasterio de El Escorial, Documentos para la historia escurialense IX, vol. I, pp. 77-78. Madrid: Patrimonio Nacional.

(43) Íñiguez Almech, F. (1965). Las Trazas del Monasterio de San Lorenzo de El Escorial, pp. 36-37. Madrid: Real Academia de Bellas Artes.

(44) Bustamante García, A. (1994). La octava maravilla del mundo, pp. 88. Madrid: Alpuerto.

(45) AGS,OyB,Escorial,leg.7.

(46) AGS,OyB,Escorial,leg.2, $\mathrm{fo}^{\circ} 109$. 
(47) IVDJ Envío 61(1), $\mathrm{f}^{\mathrm{o}} 170$.

(48) AGS,OyB,Escorial,leg.6.

(49) IVDJ Envío 61(1),ff.52-53.

(50) AGS,OyB,CySR,leg.258, f $^{\circ} 337$.

(51) IVDJ Envío 61(1),ff.327-330.

(52) RBME II-94.

(53) López Mozo, A. (2008). Tres monteas escurialenses. Revista EGA, 13: 190-197.

(54) IVDJ Envío 61(1),ff.31-32.

(55) Llaguno y Amírola, E. (1829). Noticias de los arquitectos y la arquitectura desde su restauración...ilustradas y acrecentadas con notas, adiciones y documentos, por D. Agustín Ceán Bermúdez, vol. II, pp. 227-228. Madrid: Imprenta Real.

(56) IVDJ Envío 61(1),ff.327-330.

(57) AGS,Contaduría Mayor de Cuentas, $1^{\mathrm{a}}$ época,leg.1238.

(58) IVDJ Envío 61(1),ff.82-85.

(59) AGS,OyB,CySR,Madrid,leg.3.

(60) Lasso de la Vega, M. (1945). El Rey Don Felipe II, Juan de Herrera y otros artífices de El Escorial. Rev. Escorial (53). Madrid: Emblema.

(61) RBME I-90 y II-177.

(62) RBME II-75.

(63) RBME II-45.

(64) Archivo Ayuntamiento de San Lorenzo, Docs.4259 y 4259.

(65) RBME III-5.

(66) RBME II-40 y II-175.

(67) AGS,OyB,Escorial,leg.2.

(68) RBME I-69.

(69) RBME II-64.

(70) RBME II-116. 